\title{
The Unsaid in Chomsky's Theory of Language and Pragmatics
}

\begin{abstract}
There is a common belief among EFL learners and their teachers alike that the unsaid information is a specificity of pragmatics and pragmatics only. In the domain of linguistics it is made clear that semantics and pragmatics are the two disciplines which look at the knowledge used to convey and to extract meaning when speaking or hearing someone speak. It is also clear-cut that, generally speaking, semantics is concerned with meaning that comes from linguistic knowledge, while pragmatics is concerned with meaning that takes into consideration knowledge about the social world. That is, the pragmatic meaning cannot be predicted by linguistic knowledge alone.

The aim of this paper, however, is to show that the standpoint that the unsaid information is a property of pragmatics only is debatable. The unsaid information, yet understood, is introduced in Chomsky's theory of language, namely in his transformational grammar. The only thing is, in pragmatics, the unsaid is understood by implication, whereas in Chomsky's grammar, the unsaid is understood by intuitions which are part of the speaker's language.

\section{Salah KAOUACHE}

Faculty of Letters and Languages University of Constantine 1 (Algeria)
\end{abstract}

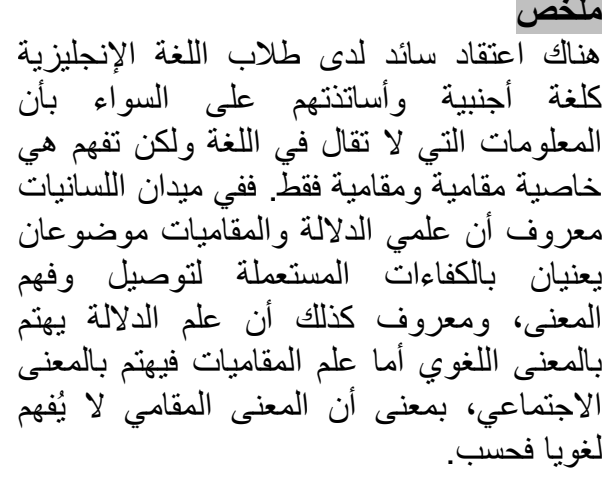

\section{Introduction}

University students of English as a foreign language and their teachers of linguistics hold the belief that the unsaid information, but understood, is a property of pragmatics only (Levinson, 1983). This is neatly reflected in the lectures delivered in classes at the level of university. This is completely contrary to the fact in that, it is felt, that the deep structure, which represents the basic meaning, which is hidden, abstract, not said, but understood, is neglected. The ability which makes the language user understand that information which is not given at the level of form - surface structure - proves that the above mentioned type of meaning is introduced in Chomsky's Grammar. 
The only thing is, sociolinguists relate it to the exposure of the speaker to his/her speech community where s/he acquires those aspects of meaning that cannot be predicted by linguistics knowledge alone, while Chomsky relates it to competence of the mind, not to behavioural habits, under the influence of Saussure's 'langue' which is the

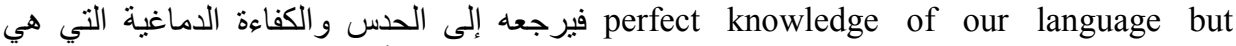
جز جزء من اللغة الأم. Which exists only within a collectivity (Saussure, 1916, 1960).

\section{Acquired or Intuitive Knowledge?}

The question which poses itself in the present context is: Is there evidence to determine that the understanding of unsaid information from a given sentence is pragmatic or intuitive? social or mental? The answer to this question is absolutely no. Consider the following example:

I was impressed by Bob's devotion to teaching.

By the look at this example, it can be inferred that:

- Bob is a teacher

- Bob is devoted to teaching, although there is nothing in the sentence which explicitly states those inferences.

That is, if pragmatically approached, and in accordance with Yule's definition "Pragmatics is the study of how more gets communicated than is said" (1996, p. 3), it can be said that the understanding of the information which is not said falls into the domain of pragmatics. But, if mentally approached, it can be said that there is a competence in man's mind which would give him the ability to make the link between the possessive case 'Bob's' and the noun 'Bob', and between the noun 'devotion' and the participle 'devoted'.

It is immediately obvious that it would be easy for any normal native speaker of English to draw the conclusion from the above example that Bob is devoted to teaching, but it is also obvious that it would be difficult to determine whether that understanding refers to the pragmatic knowledge of language or to the mental ability which Chomsky calls 'competence'. It is agreed by recent developments in linguistics theory that competence underlies the performance of the language user. By 'underlies' it is meant that there are things which do not appear in performance - the putting of competence in practice - but which are understood by individual native speakers. "Language is competence of the mind, not a system of behavioural habits" (Lepschy, 1982, p. 135). What is involved in the understanding of a sentence - surface structure the form given in everyday communication is not a technique of relating it to other sentences previously heard in society as much as it is the whole of the speaker's linguistic competence. No existing learning theory can possibly teach the users of a given language such competence; it is an innate specific feature of human beings. 
Chomsky (1957) proves that by the ability to produce and understand sentences which have never been produced before.

\section{Underlain or Implied?}

No two persons would disagree on the fact that the most interesting innovation in the domain of linguistics is the development of Chomsky's transformational generative grammar. Some people might disagree with this standpoint by claiming it was not Chomsky but Harris who has first introduced the notion of transformations in the field of linguistic theory. But Chomsky's modifications of Harris's transformations have given more importance to the semantic value of transformational rules. This can be neatly seen in 'Meaning Preservation'. That is Chomsky (1965) now, as opposed to Harris, considers that transformations are those processes (operations) in which we change form without changing meaning. He believes that it is now reasonable to think that a sentence has two levels of structure - one is abstract, representing the deep structure, the other is observable, representing the surface structure. The deep structure represents the basic meaning, while the surface structure represents form as it is given in the spoken or written form of language. The importance of the distinction between the given two structures - deep and surface - comes from such examples as ambiguous sentences as: 'I met the girl with the flowers', in that it is not clear who had the flowers, was it the speaker? or was is it the girl?

Before Chomsky, linguists would analyse only sentences in use or usage and would describe them as such. That is, the abstract side of sentences was not taken into account, only the apparent side was. By this, the sentence: 'I met the girl with flowers' would have only one description or analysis, and thus, only one meaning. Before Chomsky, no grammar was able to tell the possible meanings which are embedded within only one form. But now it can be noticed that one major function of transformations is to relate a fairly concrete surface structure that indicates its form to a more abstract deep structure that represents the basic meaning of a sentence. By this relationship the problem of meaning in structural linguistics is now finding its way to some solutions. Two descriptions are given to the sentence cited above; in one the speaker had the flowers, in the other the girl had the flowers. That is two descriptions, two meanings.

One of the functions of Chomsky's transformations is the rearrangement of constituents which can be applied to give:

I, with the flowers, met the girl.

By this arrangement ambiguity disappears - the speaker definitely had the flowers, not the girl. In fact, transformations do not operate on kernel sentences only, as Harris (1951) claims, but on more abstract structures, or strings of symbols underlying the sentences.

The basic justification for the theory of transformational grammar is now illustrated in examples like: 'Bob was convinced by Bill to stay', in which Bob is traditionally the grammatical subject of the sentence, while logically 'Bill' is subject. This shows the need for distinguishing grammatical categories (like NP, VP, etc.) from grammatical functions (like subject, object, etc.). 
Perhaps the most important functions of transformations are the deletion and insertion of constituents. Native speakers delete words and know that some words have been deleted from a piece of language. They also insert words and know that some words have been inserted in a given sentence. This knowledge ability of word deletion and word insertion can be said to be intuitive (Chomsky, 1973). It can also be described by the grammar of language (Bloomfield, 1933). To give but an example, it seems there are rules in the English language which state, for instance, that words are deleted when they are given elsewhere. They are also deleted when they are indefinite elements (Morley, 2007). Consider the following:

A man can be destroyed, but not defeated.

Notice that 'but not defeated' cannot be understood in isolation; but in relation to the first part of the sentence 'A man can be destroyed', it becomes clear that it means 'but a man cannot be defeated'. The question which poses itself here is: what makes one understand that information which is not said in the sentence? Is it a mental ability? or is it a pragmatic inference? No matter what it is, there is an involvement of one of the basic functions of transformations - the deletion of words - namely deletion under identity.

If the two sentences are lined up, the result will be:

A man can be destroyed, but a man cannot be defeated,

A man can be destroyed, but not defeated.

The result is: 'a man', 'can', and 'be' are deleted. Notice that the deleted words have not been omitted in a random way; the deletion has concerned those words which are given in the first part of the sentence. This falls into the rule which states that words which are given elsewhere can be omitted. This can be traditionally stated as to avoid needless repetition (Hogan, 2013). The aim behind that is to say that 'a man', 'can', and 'be' are unsaid but understood exactly the same way native speakers would understand that 'Ed invited Chris' in:

- Faye: I hear you've invited Mat and Chris.

- Ed: I didn't invite Mat, (Peccei, 1999, p. 33) although 'I invited Chris' was not said by Ed.

Similarly, in the dialogue between parent and child:

- Parent: Where are your shoes, young man?

- Child: Under my bed.

- Parent: When I asked where your shoes were, I wanted you to put them on (ibid. p. 6).

It is clear that, in the example just given, the child did not understand his parent's implication. He could only understand the linguistic meaning, but not the pragmatic one. Still he could understand that 'my shoes are' or 'they are' could be understood without saying them. Thus, it can be inferred that some unsaid information can be 
understood by means of grammatical competence and some unsaid information can be understood by means of pragmatic competence or communicative competence. Both are abilities which are part of the native speaker's language; both cannot possibly be learned and are a universal property.

It must be added that, in the quotation stated above, Hemingway (the author of the quotation) did not say by whom a man can be destroyed and by whom a man can be defeated. That is, the 'by-phrases' 'by someone or something' which are normally present in passive forms have been deleted. Yet, any native speaker of English would easily understand that the basic meaning of 'A man can be destroyed, but not defeated' is, in fact, 'A man can be destroyed by someone or something, but a man cannot be defeated by someone or something'. The former is, in Chomsky's term, 'the surface structure', which represents form, while the latter is, 'the deep structure', which represents the basic meaning. But that which is not said in the surface structure falls into one of the basic functions of Chomsky's transformations: 'deletion of constituents'.

For more illustration, the following can serve as a good example of the unsaid:

The problem is hard to solve.

Again, any native speaker of English would understand this sentence as:

The problem is hard (for anyone) to solve.

'For anyone' is an information which is not given; yet, it is understood. Is it a property of pragmatics? Is it a property of grammar? In any case it falls into the 'unsaid information' which Chomsky has not neglected as a function of his transformations; 'for anyone' is an indefinite element in Chomsky's terms and one has to remember that the rules suggest that indefinite elements are to be deleted.

\section{Conclusion}

The idea that the unsaid information but understood is not just a property of pragmatics but of Generative Grammar as well, runs counter the thinking of E.F.L. students and teachers of linguistics. But, after such an advance in the domain of transformational grammar, it is hoped that university EFL learners direct their thinking to a type of language study which has made of Chomsky that famous all over the world; a study which - to a great extent - succeeded to set up a kind of grammar which involves man's mind in making the form and meaning of a language compatible by relating that which is said to that which is unsaid by the use of some rules called 'transformations'. 


\section{References}

Bloomfield, L. (1933). Language. New York: H. Holt \& Co.

Chomsky, N. (1957). Syntactic structures. 's-Gravenhage: Mouton.

Chomsky, N. (1965). Aspects of the theory of syntax. Cambridge: Massachusetts Institute of Technology Press.

Chomsky, N. (1973). Conditions on transformations. In S. R. Anderson \& P. Kiparsky (Eds.), A Festschrift for Morris Halle (pp. 232-286). New York: Holt, Rinehart \& Winston.

Harris, Z. S. (1951). Methods in structural linguistics. Chicago: University of Chicago Press.

Hogan, G. B. (2013). Building better paragraphs. Boston, MA: Wadsworth, Cengage Learning Lepschy, G. C. (1982). A survey of structural linguistics. London: Deutsch.

Levinson, S. C. (1983). Pragmatics. Cambridge: Cambridge University Press.

Morley, D. (2007). The Cambridge introduction to creative writing. Cambridge: Cambridge University Press.

Peccei, J. S. (1999). Pragmatics. London: Routledge.

Saussure, F. de. (1916). Cours de linguistique générale. Lausanne: Payot.

Saussure, F. de. (1960). Course in general linguistics (W. Baskin, Trans.). London: Owen. Yule, G. (1996). Pragmatics. Oxford: Oxford University Press. 